\title{
On inadequacies in transferring concepts from one to another (linguistic sub)discipline
}

\author{
Wolfgang U. Dressler \\ Dept. of Linguistics, Vienna University and Institute for Corpus Linguistics and Text \\ Technology, Austrian Academy of Sciences \\ wolfgang.dressler@univie.ac.at
}

\begin{abstract}
The paper discusses several methodological problems in the necessary (mostly metaphorical) transfer of concepts from one discipline (or subdiscipline) into another one, especially when interdisciplinary research demands mutual understanding in terms of translation and correspondence of concepts. After differentiating between multidisciplinarity, interdisciplinarity and transdisciplinarity, the first is rejected and it is pleaded that the second and third should be combined. Several adequate and inadequate transfers of concepts into linguistics are dealt with, especially in the areas of morphology and language acquisition. Successful transfer is characterised by the formal transfer of new terms and their easy adaptation to already existing linguistic conceptions, especially between subdisciplines. Most often, further important differentiations of a concept cannot be transferred from the original discipline but must be added as enrichments within linguistics itself. This may lead to a split-up of concepts in different subdisciplines of linguistics. The concepts discussed are regression, self-organization, complexity, transparency vs. opacity, figure and ground, top-down processing, default, input, grammaticalisation.
\end{abstract}

Keywords: interdisciplinarity; language acquisition; morphology; transdisciplinarity.

\section{Introduction}

This contribution focusses on problems involved in the interdisciplinary, crossdisciplinary and subdisciplinary transfer of concepts in linguistics, i.e. general methodological questions and on a number of inadequate or successful examples in various areas of linguistics, especially in psycholinguistics. As a result it will plead for the importance of a conjunction of interdisciplinary transfer and transdisciplinary extension of concepts. 
I will not deal with simply ignoring literature in other disciplines or subdisciplines, other than briefly mentioning now two related instances: one pillar of assuming Universal Grammar (UG) is, following Chomsky, the malfamous argumentation of the poverty of stimulus for language acquiring children: still many, cf. Al Mutairi (2014), Piattelli-Palmarini (2015), critical survey in Payne et al. (2013), Yang (2015). But there is ample acquisitionist counterevidence to which also our group contributed (Kilani-Schoch et al. 2009). A related notion is Pinker's $(1984,1998)$ UG distinction between grammatical rules vs. analogy within lexicon-based stored morphology, ignoring that this distinction exists also about the development of behaviour in developmental psychology (see Pothos 2005).

\section{Interdisciplinary correspondences and transfer}

With concepts we categorize objects, events, etc. that share common properties, with the purpose of forming classes of things, events, etc. Following the principles of scientific precision we strive to establish biunique terms. But this biuniqueness may hold only within a specific field of inquiry. Thus there is no problem with the term cell having different meanings in a monastery, in biology and in statistics, e.g. a cell within a table. Another instance is the different meaning of filler in discourse analysis and pragmatics vs. in research on the acquisition of lexicon and morphosyntax. But within the same discipline (or at least subdiscipline) and within the same theoretical framework the ideal of biuniqueness should be observed as much as possible. Clearly this ideal of biuniqueness holds most for the language of theoretical science, in contrast to other domains of theoretical research and of other scientific endeavours, such as the new approaches of open science, due to the differing degree of precision intended (cf. Felber and Budin 1989; Sabatini 1999).

But what if we transcend the limits of a single discipline? Here we come to the problems of interdisciplinary and transdisciplinary research. These two notions are not always clearly distinguished (see e.g. Mittelstraß 2005; Choi and Pak 2006; Küng 2015). One common distinction is to differentiate three different ways of going beyond the limits of a single discipline: (1) additive multidisciplinarity; (2) interactive interdisciplinarity; (3) holistic, i.e. integrated transdisciplinarity.

My own distinction which I think it is more relevant for my topic of concept transfer in terms of the sociology of science, is: interdisciplinarity means co- 
operation between different disciplines, when each of them is approximately at an equal footing, although one may be the leading discipline, as it is the case in psychology of language or in sociology of language. This cooperation is typically interactive and not only additive, because mere addition would mean in the strict sense that no real correspondence is established between the respective areas. If full integration is established or at least fully intended, then it represents a new subdiscipline, as it happened in the genesis of psycholinguistics or sociolinguistics. With transdisciplinarity I designate the extension of one leading discipline into another one, which always needs interaction between the different disciplines but never full integration, because only part of the content and of the theoretical and methodological approach of the non-leading discipline is involved.

For both interdisciplinary and transdisciplinary approaches, there exist the problems of establishing correspondences between concepts of the different (sub)disciplines and of transferring concepts from one (sub)discipline to another one, including extension of concepts from one subdiscipline into another one.

My first personal experience in the problems of interdisciplinary and transdisciplinary research occurred fifty years ago when I worked on methodological problems of reconctructing the original home of the reconstructed Proto-IndoEuropean language (Dressler 1965; cf. now Anthony and Ringe 2015). The first inadequacies observed in the literature and in discussions with specialists from prehistory were the frequent equation of archeological artefacts with their producers and with their language, e.g. linear ceramics (G. Schnurkeramik) with supposed "Schnurkeramiker" and with the question whether they were speakers of a paleo-Indo-European or even of the reconstructed Proto-Indo-European language. This starts with the difficulty to distinguish who produced the fragment of a pot found in excavations, who used it and who destroyed it. A second difficulty were the limits of semantic change, such as in the question to which tree the reconstructed PIE word for 'beech' could refer, analogously for 'salmon, wheel, axle' (cf. Anthony and Ringe 2015: 201ff). A third problem was that the use of evidence from borrowing relations presupposes knowledge about the reconstruction of Proto-Kartvelian, Proto-Uralic, etc. (cf. Anthony and Ringe 2015: 206ff).

If we generalize, then: the first problem area is how to establish correspondences between categories of different fields, prototypically between two fields. In our experience of always growing specialisation this needs so much expertise in both fields that usually no single researchers are able to do it themselves but specialists of each field have to cooperate. A special case is the existence of ho- 
mophonous categories of different fields, which represent false friends, especially in adjacent subdisciplines.

A chronologically second personal experience was the (often occurring) partial illusion of apparently easy ways of obtaining external/substantial evidence for linguistic hypotheses through studying aphasia and first language acquisition, i.e. evidence for linguistic concepts from the subdisciplines of acquisitional psycholinguistics and neurolinguistics. In the course of evolution of linguistics there was first referral to rather anecdotic evidence, as often still in argumentations by Jakobson (1941), and when trying to enter systematic empirical psycholinguistic investigation, many linguists gave up. Jakobson's forerunner in both areas of acquisition and aphasia, Baudouin de Courtenay (since 1869; cf. Mugdan 1984) was more systematic and empirical.

As first example of concept transfer problems in these endeavours we can cite Jakobson's (1941) transfer of the regression hypothesis from neurology to linguistics. The Breton neurologist Théodule Armand Ribot (1881) had found out that later memorized concepts are lost earlier than earlier memorized concepts in memory diseases (cf. also Pitres 1895). And this has been elaborated especially in aphasiology. However, this regression thesis has been refuted (de Bleser and Kauschke 2003), because too many variables of typical child acquisition and of aphasic impairments are different.

Another example is the transfer of the concept of self-organization: from biology to cognitive science (Maturana and Varela 1979; von Foerster 1981) and to neurology (e.g. Singer 1987) and then to constructivist approaches to language acquisition (MacWhinney 2009, 2010; Tomasello 2003), including emergentist models (Bybee and Hopper 2001). However, one major difference between pattern selection during self-organisation in language acquisition and in cell biology or neurological development has often been neglected, namely the active role of the child in pattern selection, ultimately connected with the philosophical principle of free will. This active individual role of children shows up in interindividual variation in acquisition when it cannot be linked to differences in children's environments (Richards 1990; Lieven et al. 1992; Lust 2006: 170).

Our acquisition group has identified a particularly telling type of individual pattern selection that we have named blind alley development, i.e. when children choose an acquisition path which leads away from directions towards target language structures and the input they receive from their care-givers and environment (Bittner et al. 2003: viii-ix, xviii). One instance is that several Russian children have been observed by Gagarina (2000) to produce verbal-root re- 
duplication indicating, in an iconic way, iterative actionality or imperfective aspect. These roots are of three types:

(1) onomatopoetic or non-sense monosyllables, as in:

Vanja 1;10: bul', while the glass is in the water where it has sunk vs. bul'-bul'-bul', while the water is dripping out slowly from the glass.

Filip 1;8 sjapa n'am '(I want to) eat the hat' vs. 1;9 n'am-n'am 'I'm eating', in response to the question What are you doing?, which demands an answer in the imperfective aspect.

(2) verb roots:

Liza 1;8: kap-kap, referring to digging repeatedly with a shovel (cf. Inf. kopat' [ka'pat']).

Anton 2;6: in response to the question What are you doing?: tuk-tuk, then correct stuchu 'hammering, I'm hammering'.

(3) other parts of verb forms:

Maxim 1;4: gom-gom in reference to the boy Sasha's running (from 1.P1.Pres. begom 'we are running').

None of these patterns produced by several children has any model in the target language nor in the recorded child-directed speech of their parents. But there are many other languages where reduplication has either iterative or imperfective meaning (cf. Hurch 2005). Thus these children chose a natural iconic path of development absent in Russian and in their input, but present in many other languages. But later they had to give up this blind alley development. Similar examples were found by our international group of the Crosslinguistic Project in the Acquisition of Pre- and Protomorphology in French, German and Greek data.

\section{Subdisciplinary differences}

A felicitous concept transfer can be illustrated with contemporary concepts of grammatical complexity, as well illustrated by the recent PLM volume (Dziubalska-Kołaczyk 2014) which partially come from systems theory (e.g. Zurek 1990; Hawkins 2004). But they have old linguistic forerunners, for example Johann Gottfried Herder's (1771) Abhandlung über den Ursprung der Sprache, 
who speculated that human language originally had no morphology at all but only iconic expressions, and that morphology started with grammaticalisation and finally developed irregular patterns. This view already partially predates my own distinction between morphological richness consisting of all productive patterns and morphological complexity which, in addition, includes all unproductive morphology (Dressler 1999, 2008). Unproductive patterns can thus be subsumed under the notion of decreased predictability in complexity theory. This represents a building-block model of complexity theory, which can be easily adapted to item-and-arrangement models of linguistics, but has been also adapted to Chomsky's ideas on complexity (Hawkins 2004). Herder's ideas had much follow-up in the course of speculations on language evolution. Another tradition of comparing so-called primitive languages with contemporary European languages has been discussed by Kilarsky's (2014) paper on "complexity in the history of language study".

This successful transfer is characterised by the formal transfer of new terms and their easy adaptation to already existing linguistic conceptions. This adaptation has gone as far as to become most often entirely free of any reference to its origin in systems theory, but new transfers occur as well, e.g. from network science by Vitevitch (2014)

Work on the development of complexity has been done mostly on diachronic complexification, there is relatively little acquisitionist work with an explicit focus on complexity (e.g. Andersen 1992; Behrens 2008; Bavin 2009: 237257). In our group's work we have studied two roles of complexity in early firstlanguage acquisition: (1) morphological complexity as rendering acquisition more difficult; (2) the rise of complexity during the course of acquisition, as in Dressler (2011) on inflectional morphology.

(1) When studying morphological complexity as rendering acquisition more difficult, the advantage of our distinction between morphological richness and complexity becomes evident. Whereas greater richness in productive morphology facilitates acquisition of morphology (Dressler 2010; Xanthos et al. 2011), because it stimulates the child to focus on morphology, acquisition of complex unproductive patterns is difficult, of course beyond lexical rote learning of at least minimally frequent forms. Unproductive patterns are more complex than productive patterns, because no general and reliable morphological generalizations can be made about unproductive patterns. The graduality of this factor is reflected in our gradual model of productivity (Dressler 2008). For example, the factors of complexity that make Ger- 
man plurals more difficult to acquire than Dutch and Danish plurals are (Laaha et al. 2006, 2011; Korecky-Kröll and Dressler 2009; Ravid et al. 2008):

(a) the complexity of factors conditioning the application of competing and often unproductive patterns (rules or schemas), such as pure umlaut, as in Mutter $\rightarrow$ Mütter 'mother-s', fem. Pl. in suffix - $e$ with Umlaut, as in die Braut $\rightarrow$ Bräut-e 'bride-s', suffix -er with and without umlaut, as in Kind, Haus $\rightarrow$ Kind-er, Häus-er 'childr-en, house-s', thus not only the greater number of different plural markers itself is relevant;

(b) the resulting divergent, i.e. inhomogeneous and asymmetric frequency distributions. Lack of homogeneity means more specific learning effort;

(c) ambiguity of marking, i.e. the homophony of all plural markers (-e, $-(e) n,-e r,-s$, umlaut, zero) with other morphological markers, plus the homophony of plural patterns with singular patterns, i.e. all the plural forms cited look also like singulars;

(d) relatively little predictability of suffix choice and of the application of umlaut, e.g. in comparison to English and Dutch where high suffix predictability is close to $100 \%$, whereas we had to settle for German with a $70 \%$ threshold;

(e) disambiguation of zero plurals by articles (and in addition other modifiers);

(f) resulting inhomogeneity of distributions, including multiple exponency.

Therefore acquisition of German plural formation is a protracted process until full mastery. Clearly most of such specific complexity factors have no models in systems theory and their mathematic applications and had to be developed within linguistics itself.

(2) The rise of morphological complexity must not be confounded with the mere emergence of rote-learned forms, which the child cannot yet decompose. Only when children detect the correlation and then decomposability of form and meaning of inflectional forms and, according to the target lan- 
guage, simultaneously of compounds and diminutives, can one speak of the emergence of morphology (Dressler 2010, 2011). Very soon afterwards children generally start with creating by analogy overgeneralisations. Thus in Austrian German plural acquisition productive suffixations with $-e$ and -en are the first to emerge and to be overgeneralised, also in competition with each other, e.g. der Zug 'train', Pl. die Züg-e $\rightarrow$ Zug-en. The unproductive - er plurals emerge later and still later do the pure umlaut plurals, unless in very few rote-learned representatives with high token frequency. Thus less productive and thus more complex patterns are acquired later. The same holds for less transparent/more opaque forms, the topic of the following section. Both factors have also an impact on error frequency in tests until the end of childhood. A third factor of complexity is numeric, i.e. children slowly increase the number of morphological elements within the same word, be it affixes or elements of a compound or particle verb. Thus German particle verbs are (as in Dutch) first reduced to the stressed particle, e.g. past participles such as rúnter-ge-făll-en 'having falling down' are first produced as the separable particle or prefix runter, then as runter-fall$((e) n)$, finally with all 4 morphemes. Similarly compounds consist at first invariably of only 2 lexical elements, a third one appears late and rather infrequently. The rise of complexity in acquisition occurs successively, i.e. without jumping over intermediate stages, but differently for each category and also lexically determined. This is very different from the simultaneous detection of morphology in German verb and noun inflection, diminutive formation and compounding.

Similarly to complexity there has been a successful enriched transfer of the terms transparency and opacity and some of their properties from optics via semiotics to grammar and especially morphology, although it is sometimes confused with biuniqueness, as in the recent Amsterdam $\mathrm{PhD}$ thesis by Leufkens (2015). We owe a valid definition of transparency to Koi (1979): "Transparency to meaning [...] appears precisely when we completely cease to perceive the material shape of a sign [...] and are conscious only of its semantic sign". In applying the parameter of transparency to morphology, it has been necessary to divide it into two subparameters, that of morphotactic transparency/opacity of forms and of morphosemantic transparency/opacity of meaning (ignoring here morphopragmatic transparency; cf. Kilani-Schoch et al. 2011). Since physical transparency/opacity is gradual, i.e. forms a continuum, there have soon been attempts to graduate morphotactic transparency/opacity: the most detailed gradual 
differentiations have been attempted within models of Natural Morphology (Mayerthaler 1981; Dressler 2005: 272f.; Kilani-Schoch and Dressler 2005: 6877; and applied to Italian by Talamo et al. 2013).

However, in linguistic and especially psycholinguistic treatments of morphosemantic transparency/opacity (cf. Mayerthaler 1981: 35, 131, 164; Dressler 2005: 271f.; Kilani-Schoch and Dressler 2005: 77-86) we often find a simplifying dichotomy between either transparent or opaque. Such simplification is excusable in designing psycholinguistic experiments, namely as a device for obtaining large contrasting groups of stimuli, although, as a consequence, such groups are not homogeneous and thus are liable to distort the results of the experiments. Some scaling has been done by Shaw (1979) and, with the highest impact in the literature, by Libben (1998), who distinguished among twomember compounds between transparent-transparent, opaque-transparent, transparent-opaque, and opaque-opaque compounds. This results in a transparency scale of four degrees, but is still built up on a dichotomy between transparency and opacity. I suppose that this simplification has been also influenced by Frege's (1891) logical principle of compositionality, according to which an expression is either fully transparent or opaque. Thus a concept has been taken over from psychology and semiotics into linguistics with an undue simplification of the defining property, although graduality of morphosemantic transparency has been imminent in Paul's (1880) diachronic concept of Verdunkelung 'obscuration'.

In the recent years, we have proposed a much finer grading (into 9 degrees) in the domain of German diminutives in Ransmayr et al. (2015). This stepwise increase of morphosemantic opacity in the relation between the most current German diminutive suffix -chen and its base impacts on the type and token frequency of such diminutive formations in an electronic corpus of Austrian printed media of 8 billion word tokens and with 9,205 diminutive types (with a minimum count of 5 tokens) and 2,308,028 diminutive tokens:

(1) The most frequent type is the morphosemantically maximally transparent one, i.e. when the meaning of $X$-DIM most approaches the meaning of 'small or pragmatically modulated $X$ '. the degrees of growing opacity are:

(2) small collocational limitation, e.g. Hös + chen 'trousers-DIM' is used by default for children and women only; 
(3) stronger collocational limitation, as in the main usage of Herr-chen, Frauchen 'Mr/master-DIM, woman/mistress-DIM' for master and mistress of a pet $\operatorname{dog}$ (or cat);

(4) metaphoric meaning of the stem, as in Lüft-chen 'air-DIM' for a light breeze;

(5) very partial remainder of the meaning of the basis plus main new meaning, as in the predominant meaning of Weibchen 'wife-DIM' for a female animal in contrast to a generic male animal;

(6) weak relation to the meaning of the base, as in Ständ-chen 'stand-DIM' for 'serenade', which is usually performed while standing;

(7) only very remote lexical motivation, but still referring to something small, as in Eich-hörn-chen 'oak-horn-DIM' for 'squirrel', which eats acorns and has a head which seems to resemble a horn;

(8) acephalous derivations, i.e. without a synchronic lexical base, but with a recurring virtual base, as in Mäd-chen 'maid-DIM' with its diminutive synonyms Mäd-el, Mäd-erl, Mäd-i, which vouches for a sort of derivational cranberry morph.

(9) total synchronic morphosemantic opacity in hardly decomposable words ending in -chen.

One result of this differentiation of degrees of morphosemantic opacity is that in contrast to previous scalings of transparency/opacity we did not find a single example of the conceivable type "relatively transparent lexical base plus totally opaque diminutive suffix". In Italian we detected so far a single example of this type, which had been found to be well represented in compounds (e.g. Libben 1998), namely virgola 'comma' vs. DIM virgol-etta 'quotation mark', which refers to a bigger instead of a smaller object.

Another result is that diminutives with a real or apparent compound base are the more left-branching the more transparent they are, for example among totally transparent ones 32,278 are left-branching, e.g. Brüder-pär-chen 'brother pair-DIM', Zahlen-pär-chen 'few pairs of numbers (in lotto)', only 642 rightbranching, whereas at transparency degree 3 the relation is already 375 leftbranching vs. 278 right-branching (e.g. Werbe-pär-chen 'PR-pair-DIM', a lexi- 
cal pattern limited to human pairs of different sex and with a pejorative meaning). At transparency degree 5 there are 26 left-branching and 484 right-branching diminutives, e.g. Panda-weib-chen 'female panda, lit. Panda-wife-let' (there is no *Panda-weib, and Weib-chen itself has the main meaning 'female of an animal', as mentioned above).

A third result is that the quantitative distribution of the semantic relations between bases and. their diminutives is linked to semantically specific lexical patterns, which indicates that the often semantically undifferentiated quantitative argumentation about the importance of family size in psycholinguistics (e.g. Hay and Baayen 2002) is too simplistic.

Although such linguistic differentiations of transparency/opacity correspond to the graduality of transparency in optics, they had not been and cannot be transferred from the source discipline of optics, they must be added as enrichments within linguistics itself. For example, what could be gained by comparing our opacifying factors of minor or major collocational limitation in our degrees 2 and 3 of our transparency scale with the concept of partial absorption of transparency in optics. Or would it be better to compare it with the optical notion of attenuation as partial transmission loss? And could we successfully compare opacification by unpredictable addition of meaning in degrees 4 and following of our scale with the optical notion of turbidity or cloudiness of a liquid? This might be more promising if we were able to quantify the amount of meaning loss of the meaning of the base and of meaning addition to it. As long as we cannot achieve this, such scales have the epistemological status of an ordering typology in the logics of Hempel and Oppenheim (1936).

More difficult has been the transfer of the contrasting notions of figure and ground from gestalt psychology via semiotics (Scherer 1984: 156ff.) into linguistics. In semiotics and also in linguistics figure vs. ground is understood metaphorically as a contrast of a more important, more precise, more dynamic foreground with a less important, more pale, more static background. These properties have been split up in different ways in text linguistics vs. morphology. In a narrative the typical proponent of the figure is the hero (Dressler 1996; cf. Talmy 2000), due to his greater importance and dynamicity, in word formation it is, in reference to grammatical importance, the head (Dressler 2005: 275f.), in lexical recognition of morphological elements it is positional salience, due to the bath-tub effect, i.e. the periphery of a unit, such as the word, is easier to perceive than what is in between. Here there is a difference between adults and young children: for adults, adolescents and older children the beginning of a word is easier to identify than the end, therefore also prefixes are easier to iden- 
tify and therefore both morphotactically and morphosemantically more transparent than suffixes. This also explains preferences in abbreviations. For example, adults and adolescents abbreviate G. Schokolade 'chocolate' to Schoko. But young Austrian children abbreviate it to ['la:di] (with the childish diminutive suffix $-i$ ), due to the greater importance of the so-called recency effect than the so-called primacy effect (cf. Griffin 2002; Leybaert and Lechat 2001; Kirk and Demuth 2005). As a consequence children start to acquire unstressed suffixes earlier than unstressed prefixes.

Thus the conception of figure/ground has not been transferred into linguistics as a unitary concept.

When taking over both transparency/opacity and figure/ground from semiotics into linguistics, there has been the advantage that semiotics can be understood, since Ferdinand de Saussure and Roman Jakobson, as supplying linguistics with a partial metatheory.

Another example of split-up of a transferred concept in different linguistic domains, but with detrimental effects, has happened in the transfer of the notion of top-down processing from psychology and cognitive science into linguistics. In text linguistics the contrast between top-down and bottom-up processes refers to text understanding (Kintsch and van Dijk 1978), i.e. bottom-up processes build up comprehension from words and phrases up to text comprehension, top down processing starts with the situation context, the title and the first sentence of a text, which create in the receiver's mind expectations about the content that is to follow. The importance of this type of top-down processing shows up in the interpretation of text chunks containing a slip of the tongue or of the pen. More often than not these lapsus are corrected tacitly in comprehension due to the topdown-induced expectations about the content.

In morphology, however, e.g. in the processing of compounds, bottom-up processing refers to how the meaning of the whole can be calculated on the basis of the meanings of the component parts, top-down processing refers to how comprehension (or production) starts from the meaning of an existing compound or the respective pattern of analogous complex words. Bottom-up morphological processing seems to dominate in spontaneous adult interaction mainly in the case of complex words unknown to the receiver or of puns or of doubts on the correct understanding of what has just been said, including slips of the ear. Experimental psycholinguistic studies usually deal with the comprehension of compounds within word lists, where no real textual top-down processing can be involved (Libben 2006, 2014). This is probably due to the general disinterest of morphologists in text linguistics. As a consequence, the results of such word- 
list experiments are of very little ecological validity. It seems that in a paper submitted to the Seventeenth International Morphology Meeting in Vienna (2016), we (Irsa et al. 2016) are the first to report on experiments which deal with both types of top-down processes by experimenting with online-processing of coherent sequences of two sentences which involve three different types of top-down processing:

(1) coherence between the two sentences becomes clear only on/towards the end of the second sequence, as in: She was gentle with her styling. Her hairbrush was a soft one;

(2) the first sentence primes the target compound of the second sentence semantically: She tried to enter the gate. The doorknob just would not turn;

(3) the first sentence primes the target compound of the second sentence lexically: They had to buy a bed. The bedroom had only a mattress.

Transferred concepts may have to be subdivided even within the same subdiscipline according to intradisciplinary needs. Thus the notion of default has been taken over from computer science, where it refers to a setting or a value automatically assigned to a step or device in a computer program, except where it is explicitly blocked. In linguistics it has been mainly used as the normal choice, unless explicitly excluded by some special condition, thus very similar to Paul Kiparsky's "elsewhere condition", a notion which goes back, via his Polish teacher Jerzy Kuryłowicz, to the ancient Indian grammarian Panini. However, as Fraser and Corbett (1997) have pointed out, in morphology it is necessary to distinguish such general defaults (normal case defauts) from defaults as a last resort (exceptional case defaults), when no other solution is possible. The general default indicates in quantitative terms a clear and massive contrast between a majority default and marginal remainders. The second case of a default as a last resort has a clear predecessor in the 19th-century germanist tradition of naming the German -s-plural a "Notplural” (cf. Wegener 2002) 'emergency plural as a stopgap', for example when having to pluralize unpluralizable conjunctions, such as die unds und abers 'the ands and buts'. In this tradition the general or normal default has been subsumed under the polysemous notion of regularity. Unfortunately some linguists and psycholinguists (e.g. Clahsen 1999, including his discussants) have ignored this traditional distinction. 
A similar case has occurred with the notion of input. Also input comes from computer science and has been metaphorically transferred within the area of language acquisition to children's input from the environment.

Among many grammarians there is also the illusion that children simply acquire the respective target grammar, for example that Polish-acquiring children simply acquire the Polish target language or language variety, as it is described in grammars and dictionaries, as if this were the input to children. That may be true in the end, but their pathways of development are not determined or codetermined by target grammars but by their parental and then also peer-group input. This is shown by parents fine-tuning their input according to their children's stage of acquisition (Snow and Ferguson 1977; Snow 1995).For example, Viennese mothers start to use more and more diversified compounds in their child-directed speech (CDS) only when their children have started to produce compounds in a productive way (Dressler et al. 2010, 2012). And Iturrioz Leza (1997) has even found that Huichol mothers first simplify their grammar in CDS to such an extent that they offer their young children, on a quasi-regular basis, ungrammatical morphological constructions. Or take Turkish and Hungarian, both known for lengthy polysynthetic morphological constructions: but no Turkish or Hungarian mother uses such morphological monsters in their speech to young children. This not only represents adaptation of care-giver to child, but active language transmission activity

With regard to the relevance of input there exists an illusion among many psycholinguists: they seem to have maintained the old dichotomous distinction between speaker and hearer and to have never made a distinction which is routinely made in pragmatics (cf. Schober and Clark 1989) among hearers, i.e. a distinction of speech input among children in child-directed speech by caretakers: children pay most attention to input when they are direct addressees, already less when they are only ratified bystanders (also called auditors, e.g. when a mother challenges a pedagogical measure of her husband in the presence of their child), and generally least attention, when they are only overhearers of adult-directed speech by adults, i.e. when adults speak to each other, and a child only overhears this interaction by chance. Clearly overhearing is expected to have the least impact among types of child inputs, in contrast to the role of children as direct addressees or as ratified bystanders. But to my knowledge this has never been differentially investigated by acquisitionists.

Moreover, often psycholinguists seem to consider input-output relations in an oversimplified way, i.e. as if there were a direct relation between parental input and children's output, e.g. in frequency distributions. That is as if children 
were something like parrots, i.e. there is again no explicit differentiation for the child as hearer: With Harris (1992) we have to distinguish in a sequential order input (first especially parental), next intake, i.e. what the child really perceives sufficiently (e.g. due to the degree of saliency), then uptake, i.e. what the child constructs as an interim grammar in mental representation (clearly a black box for the analyst), and only finally the output. Thus there is no direct relation between input and output.

Thus a successful transfer of the conception of input vs. output required in acquisition studies considerable differentiation and conceptual enrichment.

A similar enriching differentiation, not respected by all specialists, has taken place in the subdisciplinary transfer of the concept of grammaticalisation from diachronic development to ontogenetic development, i.e. language acquisition. Clearly the gradual and often very slow diachronic transformation of lexical or discourse elements into grammatical categories is not the same as children's much faster process of turning either implicit differences or very fluctuating uses into explicit, steady grammatical contrasts. Therefore not all, but many acquisitionists (e.g. Slobin 2001) use grammaticisation instead of grammaticalisation in psycholinguistics. A very detailed longitudinal contrastive study on grammaticisation has been recently published by Bertinetto et al. (2015) on the acquisition of verbal aspect, actionality and tense in Italian vs. German.

\section{Conclusion}

Transfer of concepts is not only habitual but even necessary in interdisciplinary work in order to allow mutual understanding in terms of translation and correspondence of concepts. This is to a lesser degree also true for extension of concepts in transdisciplinary work. Successful interdisciplinary work demands cooperation between specialists of different disciplines, most effective if one of the prototypically two different disciplines is represented by a specialist who has extended his/her competence in a transdiciplinary way into the other field. Thus the importance of transdisciplinarity is stressed by Mittelstraß (2005) because it involves a researcher's readiness to cooperate with other disciplines, the extension of competence beyond one's own specialist domain, the capacity to reformulate one's approach accordingly and to establish a new homogeneous story. But at least this last capacity, I argue from my own experience, presupposes also some interdisciplinary cooperation. 
In order to return to my first example of interdisciplinarity, the reconstruction of the Proto-Indo-European homeland, the two cited authors, the archaeologist David Anthony and the Indo-Europeanist linguist Don Ringe explicitly state $(2015: 200)$ that they had to gain sufficient transdisciplinary competence in each other's field of specialisation in order to achieve their interdisciplinary goal.

Logically and also according to my personal experience, interdisciplinary cooperation and transdisciplinary extension of one's capacities is easier between subdisciplines and especially between different fields of the same subdiscipline, especially these fields share the same or at least a very similar methodology.

The examples presented in this contribution have illustrated both adequate and inadequate transfers of concepts. Often they had to be modified and enriched in their application to specific linguistic problems. This has been always the case when concepts had to be operationalized for empirical research. Furthermore we have seen the necessity of different enrichments of concepts due to differences between linguistic subdisciplines.

If I may end with my personal experience of inadequate transfers, they occurred when changing from one subdiscipline to another, especially when trying to "conquer" a new subdiscipline, i.e. either by change of one's main subdiscipline or by transdisciplinary extension into a new subdiscipline. Main problems observed were a long transition time for being really competent in the new subdiscipline, the danger of a slow thinning out of competence in an old subdiscipline with the illusion of being still fully competent, both in proper perception and in the perception by others. My major final suggestion is to combine interdisciplinarity with transdisciplinarity with a profound critical assessment of especially homophonous categories used.

\section{References}

Andersen, E.S. 1992. "Complexity and language acquisition influences on the development of morphological systems in children". In: Hawkins, J.A. and M. Gell Mann (eds.), Proceedings of Workshop on Evolution of Human Languages. Reading, MA: Addison-Wesley. 241-272.

Anthony, D.W. and D. Ringe. 2015. "The Indo-European homeland from linguistic and archeological perspectives”. Annual Review of Linguistics 2015(1). 199-219.

Baudouin de Courtenay, J.1869. “Einige Beobachtungen zu Kindern”. Beiträge zur vergleichenden Sprachforschung 6. 215-220.

Bavin, E.L. 2009. The Cambridge handbook of child language. Cambridge: Cambridge University Press. 
Behrens, H. 2008 (ed.). Corpora in language acquisition research. History, methods, perspectives. Amsterdam: Benjamins.

Bertinetto, P.M., E.M. Freiberger, A. Lenci, S. Noccetti and M. Agonigi. 2015. "The acquisition of tense and aspect in a morphology-sensitive framework: Data from Italian and Austrian-German children". Linguistics 53. 1113-1168.

Bittner, D., W.U. Dressler and M. Kilani-Schoch (eds.) 2003. Development of verb inflection in first language acquisition: A cross-linguistic perspective. Berlin: de Gruyter.

Bleser, R. de and C. Kauschke 2003. „Acquisition and loss of nouns and verbs: Parallel or divergent patterns?" Journal of Neurolinguistics 16. 213-229.

Bybee, J.L. and P.J. Hopper (eds.). 2001. Frequency and the emergence of linguistic structure. Amsterdam/Philadelphia: Benjamins.

Choi, B.C. and A.W. Pak. 2006. "Multidisciplinarity, interdisciplinarity and transdisciplinarity in health research, services, education and policy: 1. Definitions, objectives, and evidence of effectiveness". Clin Invest Med 29(6). 351-364.

Clahsen, H. 1999. "Lexical entries and rules of language: A multidisciplinary study of German inflection". Behavioral and Brain Sciences 22. 991-1060.

Dressler, W.U. 1965. "Methodische Vorfragen bei der Bestimmung der 'Urheimat". Die Sprache 11. 25-60.

Dressler, W.U. 1999. "Ricchezza e complessità morfologica". In: Benincà, P. et al. (eds.), Fonologia e morfologia dell'Italiano e dei dialetti d'Italia. Atti del 21. congresso SLI. Roma: Bulzoni. 587-597.

Dressler, W.U. 2005. "Word-formation in Natural Morphology". In: Štekauer, P. and R. Lieber (eds.). 2005. Handbook of word-formation. New York: Springer. 267-284.

Dressler, W.U. 2010. “A typological approach to first language acquisition”. In: Kail, M. and M. Hickmann (eds.), Language acquisition across linguistic and cognitive systems. Amsterdam: Benjamins, 109-124.

Dressler, W.U. 2011. "The rise of complexity in inflectional morphology". Poznań Studies in Contemporary Linguistics 47. 159-176.

Dziubalska-Kołaczyk, K. (ed.). 2014. Special volume on linguistic complexity. Poznań Studies in Contemporary Linguistics 50(2).

Felber, H. and G. Budin. 1989. Terminologie in Theorie und Praxis. Tübingen: Narr.

Foerster, H. von 1981. Observing systems. Seaside, CA: Intersystems Publications.

Fraser, N.M. and G. Corbett. 1997. "Defaults in Arapesh". Lingua 103. 25-57.

Frege, G. 1891. Function und Begriff. Jena: Pohle.

Gagarina, N. 2000. "The acquisition of aspectuality by Russian children: The early stages". ZAS Papers in Linguistics 15. 232-246.

Griffin, Z.M. 2002. "Recency effects for meaning and form in word selection". Brain and Language 80. 465-487.

Harris, M. 1992. Language experience and early language development: From input to uptake. Hove: Psychology Press.

Hawkins, J.A. 2004. Efficiency and complexity in grammars. Oxford: Oxford University Press.

Hay, J. and R.H. Baayen. 2002. "Parsing and productivity". Yearbook of Morphology 2001. 203-235. 
Hempel, C. and P. Oppenheim. 1936. Der Typenbegriff im Lichte der neuen Logik. Leiden: Sijthoff.

Hurch, B. (ed.). 2005. Studies on reduplication. Berlin: Mouton de Gruyter.

Irsa, T., G. Libben and W.U. Dressler. 2016. "Competition and cooperation between top-down and bottom-up processing of compounds". Paper presented at the 17th International Morphology Meeting, Vienna.

Jakobson, R. 1941. Kindersprache, Aphasie und allgemeine Lautgesetze. Uppsala.

Kilani-Schoch, M. and W.U. Dressler. 2005. Morphologie naturelle et flexion du verbe français. Tübingen: Narr.

Kilani-Schoch, M., F. Sánchez Miret and W.U. Dressler. 2011. "Towards naturalness scales of pragmatic complexity". Poznań Studies in Contemporary Linguistics 47. 237-263.

Kilarski, M. 2014. "Complexity in the history of language study". Poznań Studies in Contemporary Linguistics 50(2). 137-168.

Kintsch, W. and T. van Dijk. 1978. "Towards a model of text comprehension and production". Psychological Review 85. 363-394.

Koj, L. 1979. "The principle of transparency and semantic antinomies”. In: Pelc, J. (ed.), Semiotics in Poland. Dordrecht: Reidel. 376-406.

Köpcke, K.-M. 1998. "The acquisition of plural marking in English and German revisited: Schemata versus rules". Journal of Child Language 25. 293-319.

Korecky-Kröll, K. and W.U. Dressler. 2009. "The acquisition of number and case in Austrian German nouns”. In: Stephany, U. and M. Voeikova (eds.), Development of nominal inflection in first language acquisition: A cross-linguistic perspective. Berlin: Mouton de Gruyter. 265-302.

Küng, L. 2015. "Inter- und Transdisziplinarität. Zur Klärung von zwei in Planung und Städtebau oft verwendeten Begriffen". Available at <http://www.nsl.ethz.ch/index.php/de/content/view/full/2635/>.

Laaha, S., D. Ravid, K. Korecky-Kröll, G. Laaha and W.U. Dressler. 2006. "Early noun plurals in German: Regularity, productivity or default?" Journal of Child Language 33. 271-302.

Laaha, S., L. Kjaerbaek, H. Basbøll and W.U. Dressler. 2011. "The impact of sound structure on morphology: An experimental study on children's acquisition of German and Dutch noun plurals focusing on stem change". Acta Linguistica Hafniensia 43(2). 106-126.

Leufkens, S.C. 2015. Transparency in language. A typological study. Utrecht: LOT.

Leybaert, J. and J. Lechat. 2001. "Phonological similarity effects in memory for serial order of cued speech". Journal of Speech, Language, and Hearing Research 44. 949-963.

Libben, G. 1998. "Semantic transparency in the processing of compounds: Consequences for representation, processing and impairments". Brain and Language 61. 30-44.

Libben, G. 2006. "Why study compound processing: An overview of the issues". In: Libben, G. and G. Jarema (eds.), The representation and processing of compound words. New York: Oxford University Press. 1-21.

Libben, G. 2014. "The nature of compounds: A psychocentric perspective". Cognitive Neuropsychology 31. 8-25. 
Lieven, E.V.M., J.M. Pine and H. Dresner Barnes. 1992. "Individual differences in early vocabulary development: Redefining the referential-expressive distinction". Journal of Child Language 19. 287-310.

Lust, B. 2006. Child language: Acquisition and growth. Cambridge: Cambridge University Press.

Lleó, C. and M. Prinz. 1996. "Consonant clusters in child phonology and the directionality of syllable structure assignment". Journal of Child Language 23(1). 31-56.

MacWhinney, B. 2009. “The emergence of linguistic complexity”. In: Givón, T. and M. Shibatani (eds.), Linguistic complexity. New York: Benjamins. 405-432.

MacWhinney, B. 2010. "A tale of two paradigms". In: Kail, M. and M. Hickmann (eds.), Language acquisition across linguistic and cognitive systems. New York: John Benjamins. 17-32.

Maturana, H.R. and F.R. Varela. 1979. Autopoiesis and cognition. Boston: Reidel.

Mayerthaler, W. 1981. Morphologische Natürlichkeit. Wiesbaden: Athenäum.

Mittelstraß, J. 2005. "Methodische Transdisziplinarität". Theorie und Praxis 14(2). 18 23.

Mugdan, J. 1984. Jan Baudouin de Courtenay (1845-1929): Leben und Werk. München: Fink.

Paul, H. 1880. Prinzipien der Sprachgeschichte. Halle: Max Niemeyer

Pitres, A. 1895. "Étude sur l'aphasie chez les polyglottes". Redvue Méd 15. 873-899.

Ransmayr, J., S. Schwaiger, M. Durčo, H. Pirker and W.U. Dressler. 2015. "Graduierung der Transparenz von Diminutiven auf -chen: Eine korpuslinguistische Untersuchung". Submitted to Deutsche Sprache.

Ravid, D., W.U. Dressler, B. Nir-Sagiv, K. Korecky-Kröll, A. Souman, K. Rehfeldt, S. Laaha, J. Bertl, H. Basbøll and S. Gillis. 2008. "Core morphology in child directed speech: Crosslinguistic corpus analyses of noun plurals". In: Heike Behrens (ed.), Corpora in language acquisition research. Amsterdam: Benjamins. 25-60.

Richards, B.J. 1990. Language development and individual differences: A study of auxiliary verb learning. Cambridge: Cambridge University Press.

Sabatini, F. 1999. “'Rigidità-esplicitezza' vs. 'elasticità-implicitezza': Possibili parametri massimi peruna tipologia die testi”. Etudes Romanes 42. 141-172.

Scherer, B.M. 1984. Prolegomena zu einer allgemeinen Zeichentheorie. Tübingen: Stauffenburg.

Schober, M.F. and H.H. Clark. 1989. "Understanding by addressees and overhearers". Cognitive Psychology 21. 211-232.

Singer, W. 1987. "Activity-dependent self-organizaation of synaptic connections as a substrate of learning". In: Changeux, J.-P. and M. Konishi (eds.), The neural and molecular bases of learning. Chichester: John Wiley. 301-336.

Slobin, D.I. 2001. "Form-function relations; How do children find out what they are?" In: Bowerman, M. and S.C. Levinson (eds.), Language acquisition and conceptual development. Cambridge: Cambridge University Press. 406-449.

Talamo, L., C. Celata and P.M. Bertinetto. 2013. derIvaTario: A lexicon of annotated Italian derivatives. Pisa: Scuola Normale Superiore.

Talmy, L. 2000. Toward a cognitive semantics. Cambridge: MIT Press.

Tomasello, M. 2003. Constructing a language: A usage-based theory of language acquisition. Cambridge: Harvard University Press. 
Vitevitch, M. 2014. "Network science as a method of measuring language complexity". Poznań Studies in Contemporary Linguistics 50(2). 197-205.

Wegener, H. 2002. "Aufbau von markierten Pluralklassen im Deutschen - eine Herausforderung für die Markiertheitstheorie". Folia Linguistica 36. 261-295.

Xanthos, A., S. Laaha, S. Gillis, U. Stephany, A. Aksu-Koç, A. Christofidou, N. Gagarina, G. Hrzica, F. Nihan Ketrez, M. Kilani-Schoch, K. Korecky-Kröll, M. Kovačević, K. Laalo, M. Palmović, B. Pfeiler, M.D. Voeikova and W.U. Dressler. 2011. „On the role of morphological richness in the early development of noun and verb inflection". First Language 31. 461-479.

Yang, C. 2015. "Negative knowledge from positive evidence". Language 91. 938-953.

Zurek, W.H. (ed.). 1990. Complexity, entropy and the physics of information. Redwood City: Addison Wesly Publ. Co.

\section{Address for correspondence:}

Wolfgang U. Dressler

Department of Linguistics

University of Vienna

Sensengasse $3 \mathrm{a}$

1090 Wien

wolfgang.dressler@univie.ac.at 